\title{
LESÕES BUCAIS RELACIONADAS AOS MEDICAMENTOS MAIS PRESCRITOS PARA IDOSOS
}

Luciana Cristina OLIVEIRA, Vanessa Cristina VELTRINI

É certo que houve um aumento considerável na população idosa, e o profissional da odontologia deve ter conhecimento sobre as mudanças fisiológicas, doenças crônicas que mais acometem essa classe, os medicamentos mais usados e os efeitos que estes podem causar na cavidade bucal. O objetivo dessa pesquisa foi levantar dados sobre os medicamentos mais prescritos para idosos e as possíveis lesões bucais que poderiam causar. Foram analisados 70 prontuários de pacientes acima de 60 anos que procuraram o Projeto de Lesões Bucais do CESUMAR entre os anos de 2006 a 2008, coletando informações quanto ao medicamento usado continuamente, e lesões relacionadas aos fármacos utilizados. Do total da amostra, 49 (70\%) eram do sexo feminino, e 21 (30\%) masculino. Entre os prontuários analisados, 7 (10\%) não continham informação sobre medicamentos, e 18 (25,7\%) afirmavam que o paciente não fazia uso de nenhum medicamento contínuo. Os fármacos mais citados entre os 45 prontuários de pacientes que usavam medicamentos diariamente foram: Captopril (33,3\%), Nifedipina (22,2\%), AAS (15,5\%), Atenolol (15,5\%), Propanolol (15,5\%), Simvastatina (13,3\%), Benzodiazepínicos (8,9\%) e Fluoxetina (6\%). Apenas a Nifedipina teve maior relação com lesão bucal, tendo 3 casos de hiperplasia gengival entre os pacientes que faziam uso desse medicamento.

Palavras-chave: Hiperplasia gengival, Odontologia geriátrica, Odontologia para idosos. 